\title{
Active Soil Pressure of Unsaturated Soil under Rainfall Conditions
}

\author{
Qizhi Hu and Yugang Li \\ School of Civil Engineering, Architecture and Environment, Hubei University of Technology, Wuhan, Hubei 430068, China \\ Correspondence should be addressed to Yugang Li; 101900544@hbut.edu.cn
}

Received 3 December 2021; Accepted 12 January 2022; Published 6 February 2022

Academic Editor: Roberto Nascimbene

Copyright (c) 2022 Qizhi Hu and Yugang Li. This is an open access article distributed under the Creative Commons Attribution License, which permits unrestricted use, distribution, and reproduction in any medium, provided the original work is properly cited.

To study the change in unsaturated active earth pressure under rainfall conditions, based on the thin layer element method and shear strength formula of unsaturated soil, Iverson analysis was used to improve the traditional Coulomb earth pressure theory, and the active earth pressure formula of unsaturated soil considering the change in matric suction was derived under rainfall infiltration conditions. The results show that the active soil pressure of unsaturated soil considering rainfall is greater than that without rainfall. With the continuous occurrence of rainfall infiltration, the active soil pressure of unsaturated soil first increases, then decreases and finally tends to be stable. The above phenomenon is caused by the change in matric suction during rainfall infiltration.

\section{Introduction}

The calculation of earth pressure is always a basic subject in the field of soil mechanics. The traditional Coulomb earth pressure theory gives the mechanical geometric relation of a triangular wedge in a static equilibrium state, deduces the expression of the reaction force behind the wall, and uses the differential method to solve for the earth pressure. The formula can accurately calculate the active earth pressure of backfill in the saturated state, but the error in the calculation of the active earth pressure of unsaturated soil is large, and the influence of matric suction on the unsaturated soil is not considered in essence.

To explore the calculation of active soil pressure of unsaturated soil, a large number of scholars have studied unsaturated soil under rainwater infiltration: The Iverson and Richards equation model was adopted for the rainfall effect in the soil matric potential solution; combined with the relevant data with the experimental measurement parameters and rainfall precipitation under matric potential solutions, the parsing is divided into rainfall processes and after the two stages, expressed as filling time, rainfall and the groundwater infiltration depth function, thus simplifying the calculation of matric potential [1]. To calculate Rankine earth pressure under rainfall conditions, Wang Dingjian extended the Bishop empirical formula and Iverson analysis to Rankine earth pressure theory, deduced the Rankine earth pressure formula of rainfall infiltration, and then found that the formula was related to rainfall time and filling depth [2]; Based on the shear strength criterion, Zhao Junhai proposed that intermediate principal stress and the material pull-topressure ratio have an impact on earth pressure. By combining Iverson analysis and the effective stress principle, the Rankine earth pressure formula considering intermediate principal stress and the material pull-to-pressure ratio under rainfall conditions was determined [3]. Wang Yang and Wang Xiaoliang established a calculation model of Rankine soil pressure under rainfall and evaporation conditions by taking into account the influence of double stress on shear strength and referring to the flow control equation of unsaturated soil $[4,5]$. To discuss the influence of steady flow on Rankine earth pressure, Chen Qian established a onedimensional steady flow active earth pressure model for unsaturated soil based on the shear strength criterion. Compared with the traditional Rankine earth pressure theory, the above improved theory considered the influence of rainfall infiltration and steady seepage on earth pressure and improved the research of Rankine earth pressure theory in the direction of infiltration. However, the above study only applied to vertical and smooth retaining walls, and the 
internal friction coefficient of the material was not considered [6]. Xu Riqing et al. considered the calculation method of water-earth pressure, in which the combined method of soil and water considers that free water can be included in the combined water in soil, and the soil pressure is calculated according to the weight of saturated soil; namely, the combined calculation of soil and water pressure. This method is suitable for calculating soil pressure in cohesive soil but ignores the change in pore water pressure in soil. The soil and water partitioning algorithm considers that pore water pressure can be expressed by hydrostatic pressure to calculate the filling weight and pore water pressure, respectively. Although the formula calculation of the subalgorithm is complicated and related parameters are difficult to determine, it can intuitively reflect the contribution of matric suction to unsaturated soil pressure [7]. Through one-dimensional steady-state flow analysis, Hong Wenzhen et al. established a shear strength formula taking matric suction into account, in which matric suction is expressed as a function of seepage rate, which is difficult to measure without considering seepage rate [8].

The above research provides a reference for the calculation of unsaturated soil pressure under seepage conditions. Therefore, the rainfall infiltration mechanism can be applied to Coulomb earth pressure theory, and combined with the shear strength formula of unsaturated soil and the thin layer element method, the active soil pressure formula of unsaturated soil under rainfall infiltration can be derived, and the difference between unsaturated soil and saturated soil can be explored through a calculation example verification method.

\section{Changes in Matric Potential and Matric Suction of Unsaturated Soil under Rainfall}

For the calculation of unsaturated soil pressure under rainfall conditions, the core problem is how to describe the variation rule of matric potential in unsaturated soil [7-10]. The matric potential change refers to the potential energy change of the pore water of soil particles under the action of adsorption. The change in potential energy inevitably leads to a change in negative pore water pressure; that is, a change in matric suction.

Iverson used the Richards growth function to establish the calculation model of matric potential under rainfall infiltration. In this model, the influence of horizontal infiltration on matric potential is ignored, the influence of groundwater infiltration on soil pressure is considered, and the rainfall intensity is optimized as the standardized infiltration rate $I_{z} / K_{z}$, which simplifies the calculation of matric potential. The Iverson model assumes that the soil surface is flat and that the dip angle between the soil surface and the horizontal plane is $\beta$. The matric potential changes with rainfall infiltration time $T$, as shown below:

$$
\begin{aligned}
& \psi(z, t \leq T)=(z-d)\left(\cos ^{2} \beta-\frac{I_{z}}{K_{z}} \cos \beta\right)+\frac{I_{z}}{K_{z}}, \\
& {\left[\left(\frac{t D}{\pi}\right)^{1 / 2} \cdot \exp \left(-\frac{z^{2}}{t D}\right)-z \cdot \operatorname{erfc}\left(\frac{z^{2}}{t D}\right)\right]} \\
& \psi(z, t>T)=\psi(z, t \leq T)-\frac{I_{z}}{K_{z}} \\
& \left\{\left[\frac{(t-T) D}{\pi}\right]^{1 / 2} \cdot \exp \left[-\frac{z^{2}}{(t-T) D}\right]-z \cdot \operatorname{erfc}\left[\frac{z^{2}}{(t-T) D}\right]\right\}
\end{aligned}
$$

where the $\mathrm{x}$ axis is parallel to the surface of the fill (assuming that the surface of the fill is horizontal) and the $z$ axis is perpendicular to the surface of the fill; $\psi(z, t)$ is the pressure head at fill depth $z$ that changes with rainfall infiltration time $t ; d$ is the steady-state groundwater level in the $z$ direction; $T$ is rainfall duration; $I_{z}$ is the infiltration coefficient along the $z$ direction; $K_{z}$ is the permeability coefficient along the $z$ direction; $D=4 D_{0} \cos \beta, D_{0}$ is saturation water diffusivity; and $\operatorname{exfc}(x)$ is a residual error function.

The above analysis can be divided into two stages: rainfall processes and post-rainfall processes. The change in matric potential during the rainfall process is composed of steadystate analysis and dynamic analysis. The steady-state analysis refers to the matric potential of soil without rainfall infiltration, and the dynamic analysis describes the changing trend of matric potential during continuous rainfall. The analysis of matric potential in the post-rain process is composed of steady-state analysis and dynamic analysis. The steady-state analysis of matric potential in this stage is the instantaneous value at the end of rainfall, while the dynamic analysis of matric potential describes the changing trend of matric potential after the end of rainfall.

For the definition of matric suction, it is generally believed in the field of soil mechanics that pore gas pressure $u_{a}$ in unsaturated soil is greater than pore water pressure $u_{w}$, and the difference is matric suction (expressed by $s$ ):

$$
s=u_{a}-u_{w},
$$

where the unit of $s$ is kpa.

Taking the surface as the boundary condition, the pore gas pressure at the surface is set to $0 \mathrm{kPa}$, and the pore water pressure is set to $u_{w}=\psi \gamma_{w}$ when the filling depth is $\mathrm{z}$. Since the pore water pressure is negative, the relationship between matric suction and matric potential can be determined by combining (2):

$$
s=\left|\psi \cdot \gamma_{w}\right|=\left|\psi(z, t) \cdot \gamma_{w}\right|
$$

where $\gamma_{w}$ is the weight of water and $9.8 \mathrm{kN} / \mathrm{m}^{3}$ is used. 


\section{Considering the Matric Suction Variation of Unsaturated Active Soil Pressure}

The traditional Coulomb earth pressure theory assumes that the backfill of the damaged wall is a triangular rigid sliding wedge, and the sliding of the wedge produces two sliding surfaces in the limit equilibrium state: the sliding surface between the wedge and the back of the wall is written as $S_{c r 1}$; the failure surface of the backfill is denoted as $S_{c r 2}$; and the angle between $S_{c r 2}$ and the horizontal surface is denoted as $\theta$.

Coulomb theory considers the wedge in reaction $R\left(S_{c r 2}\right.$ acts on the wedge force), $G$ (wedge) gravity and gravity wall back reaction $e$ (retaining wall on the wedge force) in static equilibrium under the action of the static equilibrium of the limit state. It can be concluded that the wedge state of limit equilibrium finally clears the Coulomb's earth pressure equal to the wall back reaction $e$ extremum.

To further develop the derivation of the Coulomb earth pressure formula for unsaturated soil, the following assumptions are supplemented based on the assumptions of traditional Coulomb earth pressure theory [11]:(1) horizontal penetration is not considered; (2) the filling soil on the back of the wall is homogeneous sandy soil, and the wall has a dip angle; (3) dip angle of the fill surface is $\beta=0^{\circ}$; (4) there is no uniform load on the surface of the fill; (5) the failure surface is a plane $S_{c r 2}$ with shear stress; (7) the influence of rainfall on internal friction angle $\varphi$ and external friction angle $\delta$ is not considered; (8) the effective internal friction angle $\varphi^{\prime}$ of sandy soil is taken as the internal friction angle $\varphi$; (9) when the wedge is damaged, it slides along the horizontal direction, namely, translation; and (10) the stress acting on the thin layer element is uniformly distributed along the edge of the thin layer.

In Figure 1, the retaining wall height is $\mathrm{H}, \mathrm{AB}$ is the sliding surface $S_{c r 1}, \mathrm{BC}$ is the failure surface $S_{c r 2}$, and the back dip angle of the wall is $\alpha$.

3.1. Derivation of the active earth pressure formula of non-sum soil under rainfall conditions. Taking the element abcd of the wedge block in Figure 1 and the height of the element as $d z$, the strain diagram of the element in translational mode is shown as follows.

The stress distribution of the element body is simplified in Figure 2. The length of side ab is $\overline{a b}=d z / \cos \alpha$, where $p$ is the reaction stress of the retaining wall acting on the element body, and $f$ is the friction stress between the wall back and the element body. The side length of $\mathrm{cd}$ is $\overline{c d}=d z / \cos \theta$, where $\sigma_{r}$ is the reaction stress of undamaged soil on the element body. $\tau_{r}$ is shear stress at the edge of element body cd. $\sigma_{q}$ is the gravitational stress of the element body. $\sigma_{n}$ is the normal stress on the side of element body ad, and $\sigma_{n}+d \sigma$ is the normal stress on the side of element body bc. Since the element body is sufficiently small, the influence of $\sigma_{n}$ and $\sigma_{n}+d \sigma$ on the element body is ignored.

The gravity of unsaturated soil is closely related to soil saturation. The Van Genuchten hydraulic characteristic equation describes the relationship between effective saturation and matric suction, which can be expressed as:

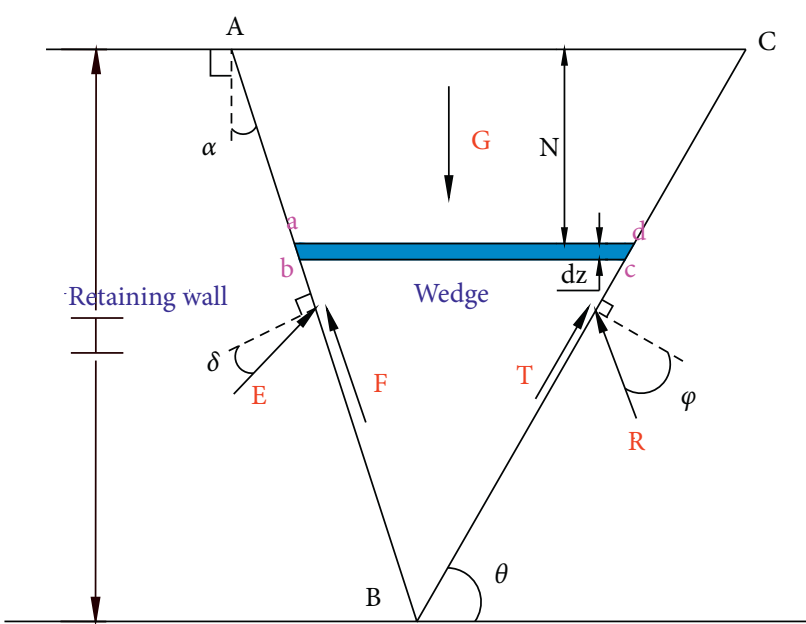

FIgURE 1: Calculation model of active earth pressure.

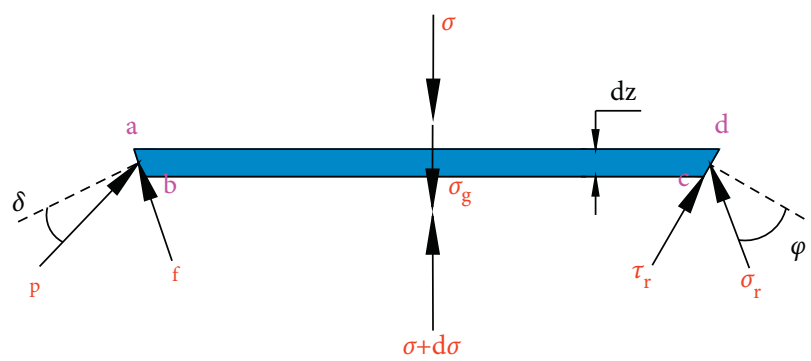

Figure 2: Stress distribution of the element body.

$$
\chi=\frac{S-S_{r}}{1-S_{r}}=\left\{\frac{1}{1+\left(\lambda \cdot\left|\psi \cdot \gamma_{w}\right|\right)^{\eta}}\right\}^{1-1 / \eta},
$$

where $\chi$ is the effective saturation; $S$ is saturation; $S_{\mathrm{r}}$ is residual saturation; and $\lambda$ and $\eta$ are fitting parameters.

Given that the Iverson solution is the matric potential, the unsaturated soil weight of the unit can be obtained by combining the effective saturation in (4):

$$
\gamma=\gamma_{d}+\chi \cdot\left(\gamma_{s}-\gamma_{d}\right)
$$

where is the gravity of unsaturated sandy soil; $\gamma_{d}$ is the dry weight of sandy soil; $\chi$ is the effective saturation; and $\gamma_{s}$ is the density of saturated sandy soil.

Formula (5) shows that when the matric suction is $0 \mathrm{kPa}$ and the effective saturation is $\chi=1$, the soil is in a saturated state and the soil weight is that of saturated soil. When the matric suction is sufficiently large, the effective saturation $\chi$ approaches 0; that is, the soil is in a dry state and the unsaturated gravity is $\gamma_{d}$.

When the dip angle of the fill is $\beta=0^{\circ}$, the Iverson matric potential is analytically the same at the same depth. Since the unit body is sufficiently small, it is considered that the weight of the unit body remains unchanged; therefore, the gravity of the unit body $d G$ should be equal to the product of the unit body weight and the unit body area: 


$$
d G=\frac{1}{2}(\overline{a d}+\overline{b c}) \gamma d z=\frac{\gamma(H-z) \cos (\theta-\alpha)}{\cos \alpha \sin \theta} d z
$$

The reaction force $d E$ between the wall back and the element body is equal to the product of the reaction stress $p$ and the edge ab of the element body, and its magnitude is:

$$
d E=p \cdot \overline{a b}=\frac{p d z}{\cos \alpha} .
$$

Then, the frictional force $d F$ of the element body:

$$
d F=d E \cos \delta \tan \delta=\frac{\cos \delta \tan \delta}{\cos \alpha} p d z
$$

The reaction force $d R$ between the undamaged soil mass and the element body is:

$$
d R=\sigma_{r} \cdot \overline{c d}=\frac{\sigma_{r} d z}{\sin \theta} .
$$

For the cd side shear stress, Bishop deduced an unsaturated soil shear strength formula based on the effective stress principle. In this formula, the Van Genuchten hydraulic characteristic equation is used to establish the shear strength of unsaturated sandy soil considering effective matric suction [9]:

$$
\tau_{r}=\left[\left(\sigma-u_{a}\right)+\chi s\right] \cdot \tan \varphi^{\prime},
$$

where $\sigma-u_{a}$ is the effective stress, and $\sigma-u_{a}$ is taken as $\sigma_{r} \cos \varphi^{\prime}$

According to equation (8), the side shear force of element body ad is:

$$
\begin{aligned}
d T= & \left(\sigma_{r} \cos \varphi^{\prime}+\chi s\right) \cdot \tan \varphi^{\prime} \cdot \frac{d z}{\sin \theta}=\frac{\sigma_{r} d z}{\sin \theta} \cos \varphi^{\prime} \tan \varphi^{\prime} \\
& +\chi s \frac{\tan \varphi^{\prime}}{\sin \theta} d z
\end{aligned}
$$

According to the static equilibrium conditions of Coulomb's earth pressure theory, the equilibrium equation of the horizontal force acting on the element body is:

$$
\begin{gathered}
d E \quad \cos (\delta+\alpha)-d F \sin \alpha+d T \cos \theta \\
-d R \sin \left(\theta-\varphi^{\prime}\right)=0 .
\end{gathered}
$$

Reduction:

$$
\frac{\sigma_{r}}{\sin \theta} d z=\frac{1}{A_{1}} \frac{A_{2} \cdot p}{\cos \alpha} d z-\frac{1}{A_{1}} \frac{\chi s \tan \varphi^{\prime}}{\tan \theta} d z,
$$

where $A_{1}$ is $\cos \varphi^{\prime} \tan \varphi^{\prime} \cos \theta-\sin \left(\theta-\varphi^{\prime}\right)$; and $A_{2}$ takes $\sin \alpha \cos \delta \tan \delta-\cos (\delta+\alpha)$.

Then, the balance equation of the vertical force acting on the element body is:

$$
\begin{gathered}
d E \quad \sin (\delta+\alpha)+d F \cos \alpha+d T \sin \theta \\
+d R \cos \left(\theta-\varphi^{\prime}\right)-d G=0
\end{gathered}
$$

Reduction:
$A_{3} \frac{p d z}{\cos \alpha}=\frac{\gamma(H-z) \cos (\theta-\alpha)}{\cos \alpha \sin \theta} d z-\chi s \tan \varphi^{\prime} d z-A_{4} \frac{\sigma_{r}}{\sin \theta} d z$,

where $A_{3}$ is $\sin (\delta+\alpha)+\cos \alpha \cos \delta \tan \delta$; and $A_{4}$ takes $\cos \left(\theta-\varphi^{\prime}\right)+\sin \theta \cos \varphi^{\prime} \tan \varphi^{\prime}$.

By substituting (13) into equation (15) to eliminate the reaction force $d R$, the analytical expression of $d E$ can be obtained:

$$
\begin{aligned}
d E= & \frac{A_{1}}{A_{1} A_{3}+A_{2} A_{4}} \frac{\gamma(H-z) \cos (\theta-\alpha)}{\cos \alpha \sin \theta} d z \\
& +\chi s \tan \varphi^{\prime}\left[\frac{A_{4}}{A_{1} \tan \theta}-1\right] \frac{A_{1}}{A_{1} A_{3}+A_{2} A_{4}} d z .
\end{aligned}
$$

Therefore, the resultant force of the unsaturated earth wall back reaction considering the change in matric suction is:

$$
\begin{aligned}
E= & \int_{0}^{H} \frac{p}{\cos \alpha} d z=\int_{0}^{H}\left[\gamma_{d}+\chi \cdot\left(\gamma_{s}-\gamma_{d}\right)\right](H-z) d z \\
& \cdot \frac{\cos (\theta-\alpha)}{\cos \alpha \sin \theta} \cdot \frac{A_{1}}{A_{1} A_{3}+A_{2} A_{4}} \\
& +\tan \varphi^{\prime}\left[\frac{A_{4}}{A_{1} \tan \theta}-1\right] \frac{A_{1}}{A_{1} A_{3}+A_{2} A_{4}} \cdot \int_{0}^{H} \chi s d z .
\end{aligned}
$$

MATLAB software is used to determine $\theta$ corresponding to the maximum value of the wall back reaction force $E$, which was recorded as the active angle $\theta_{c r}$ and substituted into (17) to obtain the active earth pressure $E_{a}$ of unsaturated soil under rainfall conditions:

$$
E_{a}=E\left(\theta_{c r}\right) .
$$

If the fill on the back of the wall is in the saturated state, the effective saturation is $\chi=0$, the matric suction is $s=0$, and the fill weight is $\gamma=\gamma_{s}$. After simplifying (17), MATLAB software is used to find the active earth pressure $E_{a}$ of saturated soil under rainfall conditions:

$E_{a}=\int_{0}^{H} \gamma_{s}(H-z) d z \cdot \frac{\cos \left(\theta_{c r}-\alpha\right)}{\cos \alpha \sin \theta} \theta_{c r} \cdot \frac{A_{1}}{A_{1} A_{3}+A_{2} A_{4}}\left(\theta_{c r}\right)$.

If the frictional stress on the ab side and shear stress on the bc side are not taken into account and the backfill is in a saturated state, then, friction force $F=0$ and shear force $T=0$. Combining (12) and (14), the simplification can be obtained by the earth-moving pressure $E_{a}$ :

$$
\begin{aligned}
E_{a} & =\int_{0}^{H} \frac{\gamma_{s}(H-z) \cos (\theta-\alpha)}{\cos \alpha \sin \theta} d z \cdot\left[\sin (\delta+\alpha)+\frac{\cos (\delta+\alpha)}{\tan \left(\theta-\varphi^{\prime}\right)}\right] \\
& =\frac{\gamma_{s} H^{2}}{2} \frac{\cos (\theta-\alpha)}{\cos \alpha \sin \theta} \cdot \frac{\sin \left(\theta-\varphi^{\prime}\right)}{\cos \left(\alpha+\delta+\varphi^{\prime}-\theta\right)} .
\end{aligned}
$$

Equation (19) is the traditional Coulomb active earth pressure formula. 
3.2. Derivation of the active soil pressure intensity formula for unsaturated soil under rainfall conditions. For the calculation of the active earth pressure intensity of unsaturated soil under rainfall conditions, an equilibrium equation was established to derive the active earth pressure intensity formula of unsaturated soil based on the stress state of the element body in Figure 2.

The gravity stress $\sigma_{g}$ of the element body is obtained from the unsaturated soil gravity:

$$
\sigma_{g}=z \gamma
$$

The relation between friction stress $f$ and reaction stress $p$ of the element body is:

$$
f=p \cos \delta \tan \delta .
$$

The shear stress $\tau_{r}$ on the edge of element $\mathrm{cd}$ is:

$$
\tau_{r}=\left(\sigma_{r} \cos \varphi^{\prime}+\chi s\right) \cdot \tan \varphi^{\prime} .
$$

The horizontal stress balance equation of the element body is:

$$
p \cos (\delta+\alpha)-f \sin \alpha+\tau_{r} \cos \theta-\sigma_{r} \sin \left(\theta-\varphi^{\prime}\right)=0 .
$$

It can be obtained by simplification of equation (24):

$$
\sigma_{r}=\frac{A_{2} \cdot p}{A_{1}}-\frac{1}{A_{1}} \chi s \tan \varphi^{\prime} \cos \theta .
$$

The vertical stress balance equation of the element body is:

$$
p \sin (\delta+\alpha)+f \cos \alpha+\tau_{r} \sin \theta+\sigma_{r} \cos \left(\theta-\varphi^{\prime}\right)-\sigma_{g}=0
$$

It can be obtained by simplification of equation (26):

$$
A_{3} p=\gamma z-\chi s \tan \varphi^{\prime} \sin \theta-A_{4} \sigma_{r} .
$$

The analytical expression of reaction stress $p$ is obtained by combining (25) and (27):

$$
\begin{aligned}
p= & \frac{A_{1}}{A_{1} A_{3}+A_{2} A_{4}}\left[\gamma_{d}+\chi \cdot\left(\gamma_{s}-\gamma_{d}\right)\right] z \\
& +\chi s \tan \varphi^{\prime}\left[\frac{A_{4}}{A_{1}} \cos \theta-\sin \theta\right] \frac{A_{1}}{A_{1} A_{3}+A_{2} A_{4}} .
\end{aligned}
$$

Substituting $\theta_{c r}$ into equation (28) and using the Sign function to optimize $p<0$ to $p=0$, that is, stress $p$ tension is not taken into account, then the distribution of active earth pressure strength of unsaturated soil along the wall height under rainfall conditions $\sigma_{a}$ is:

$$
\sigma_{a}=\operatorname{sign}\left\{\operatorname{sign}\left[p\left(\theta_{c r}\right)\right]+1\right\} * p\left(\theta_{c r}\right)
$$

\section{Case Study}

Taking a retaining wall as the analytical object, the back dip angle of the wall is $\alpha=30^{\circ}$, the surface level of the fill is $\beta=0^{\circ}$, the height of the retaining wall is $H=6 \mathrm{~m}$, the weight of saturated sand is $\gamma_{s}=20 \mathrm{kN} / \mathrm{m}^{3}$, the dry weight of sand is $\gamma_{d}=17 \mathrm{kN} / \mathrm{m}^{3}$, the saturated permeability coefficient is $K_{z}=10^{-5} \mathrm{~m} / \mathrm{s}$, and the position water level is $d=15 \mathrm{~m}$. The rainfall duration is $T=10^{4} \mathrm{~s}$, the rainfall intensity is simplified to the standardized infiltration rate $I_{z} / K_{z}, I_{z} / K_{z}=0$ is not considered rainfall, and $I_{z} / K_{z}>0$ is considered rainfall. Related parameters of backfill are shown in Table 1.

If the standardized infiltration rate is set as $I_{z} / K_{z}=0$ and $I_{z} / K_{z}=0.3$, the change in active soil pressure $T=10^{4} \mathrm{~s}$ of unsaturated soil when the rainfall duration is $E_{a}$ is shown in Figure 3.

Figure 3 shows that when rainfall is not considered, the active earth pressure of unsaturated sand has a certain value, which has nothing to do with rainfall infiltration time. When considering rainfall, the active earth pressure of unsaturated sandy soil increases with the continuous occurrence of rainfall and reaches a maximum at the end of rainfall. With increasing rainfall infiltration time, the active soil pressure of unsaturated sandy soil first decreases and finally tends to be stable.

According to equations (18) and (19), the active earth pressure intensity of unsaturated sandy soil at rainfall infiltration time is calculated, as shown in Figure 4.

Figure 4 shows that when unsaturated sand is close to the top of the retaining wall, it is subjected to tensile stress, and the active earth pressure intensity is $0 \mathrm{kPa}$. In addition, in the compressive stress region of unsaturated soil, when the retaining wall height is constant, unsaturated soil $\sigma_{a}$ considering rainfall is larger than unsaturated soil $\sigma_{a}$ not considering rainfall, and the difference increases with the increase of retaining wall height. The reason for the difference between the calculated results of the two standardized infiltration rates is that the effect of rainfall on matric suction is considered in the standardized infiltration rate $I_{z} / K_{z}=0.3$.

If only the influence of rainfall on unsaturated soil is considered, the standardized infiltration rates are, $I_{z} / K_{z}=0.05, \quad I_{z} / K_{z}=0.1, \quad I_{z} / K_{z}=0.15, \quad I_{z} / K_{z}=0.2$, $I_{z} / K_{z}=0.25, I_{z} / K_{z}=0.3, I_{z} / K_{z}=0.35$ and $I_{z} / K_{z}=0.4$, and the parameters in the example are used to calculate the active earth pressure of unsaturated sandy soil at the timexml of rainfall infiltration through equations (18) and (19). The calculated results are as follows.

As shown in Figure 5, with increasing standardized infiltration rate, the active earth pressure of unsaturated sand continues to increase. The higher the standardized infiltration rate is, the more inclined the curve of active earth pressure $E_{a}$, and the faster the increase rate of active earth pressure $E_{a}$. This is because the higher the standardized infiltration rate is under the same rainfall time, the lower the matric suction, and the higher the unsaturated soil weight.

To further analyze and consider the change law of active earth pressure of unsaturated soil during rainfall, the standardized rainfall infiltration times $I_{z} / K_{z}=0.1$, $I_{z} / K_{z}=0.2, I_{z} / K_{z}=0.3$ and $I_{z} / K_{z}=0.4$ are taken, and the active earth pressure intensity of unsaturated sandy soil at rainfall infiltration time is calculated from equation (29). 
TABLE 1: Engineering filling parameters.

Angle of internal friction $\varphi^{\prime} /\left(^{\circ}\right)$

\begin{tabular}{lllll}
\hline 30 & 15 & 1.89 & 0.1 & 0.025 \\
\hline
\end{tabular}

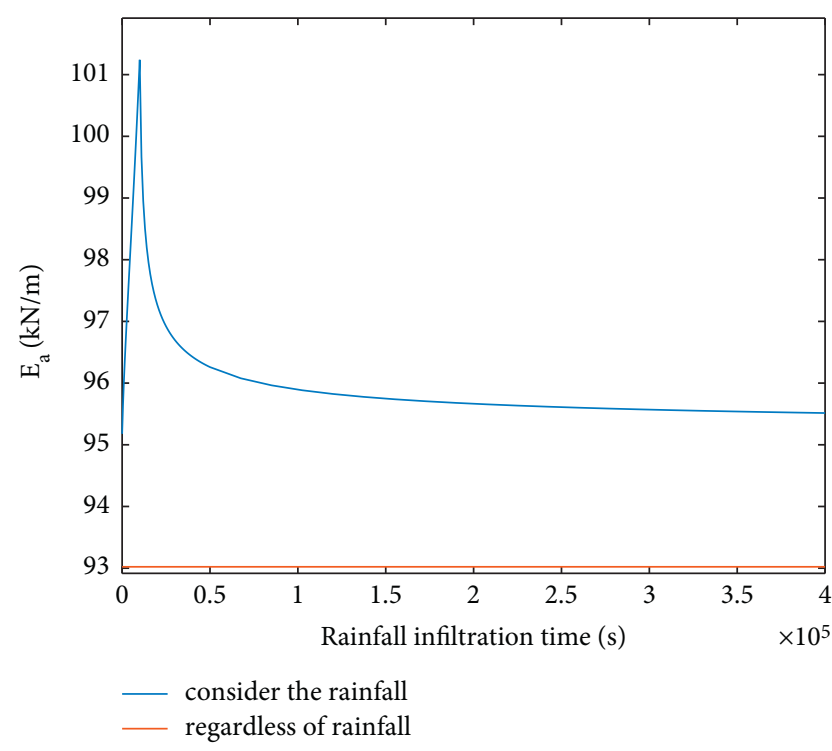

FIGURE 3: Variation in unsaturated sandy soil $E_{a}$ with rainfall infiltration time.

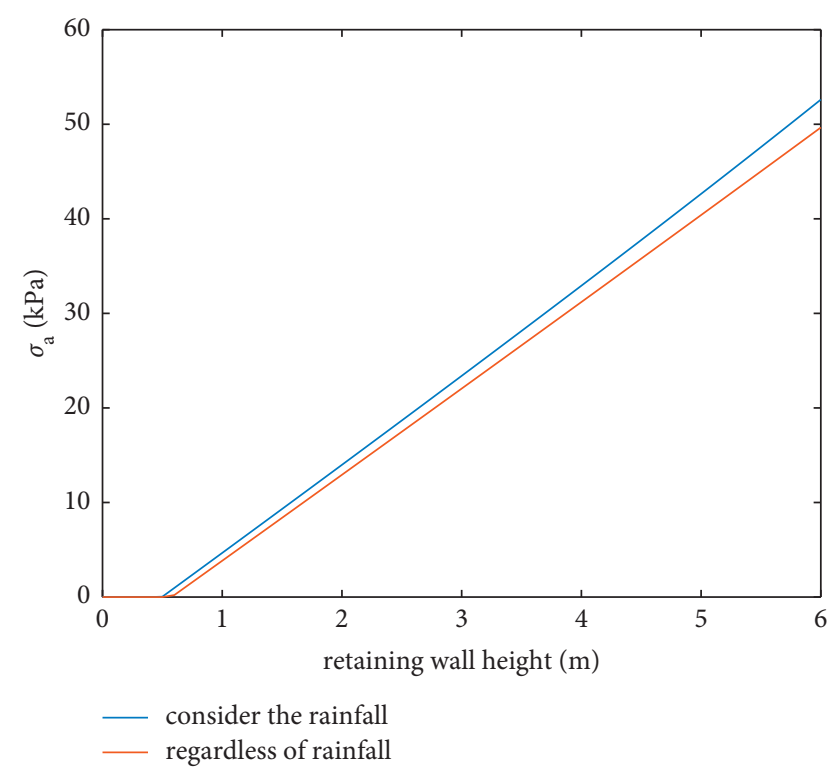

FIGURE 4: $\sigma_{a}$ variation with retaining wall height $\mathrm{H}$.

Figure 6 shows that when the standardized infiltration rate is constant, the active soil pressure strength of unsaturated soil increases linearly with increasing retaining wall height. When the retaining wall height is constant, the active soil pressure strength of unsaturated soil increases with increasing standardized infiltration rate. The trend increases

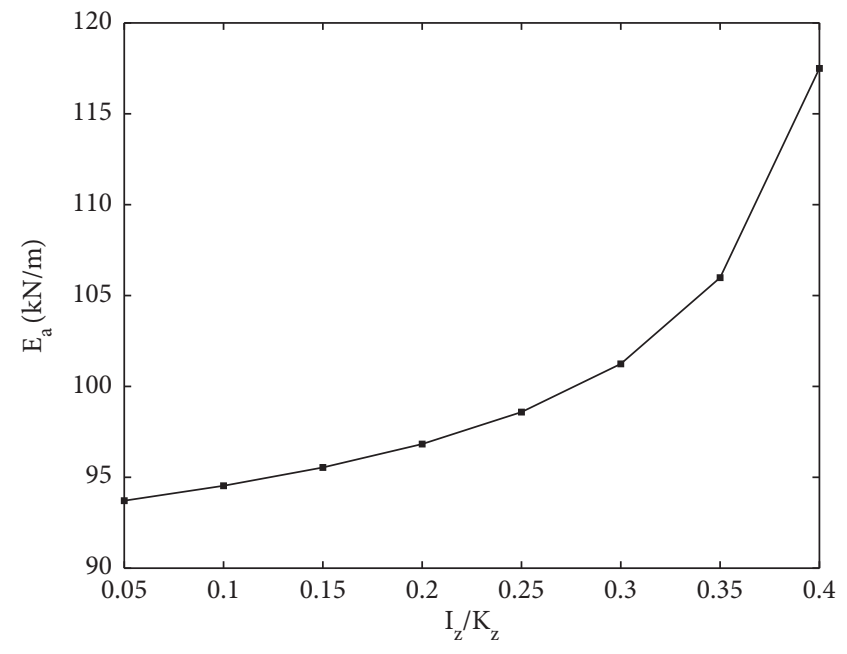

FIGURE 5: $E_{a}$ changes with standardized infiltration rate.

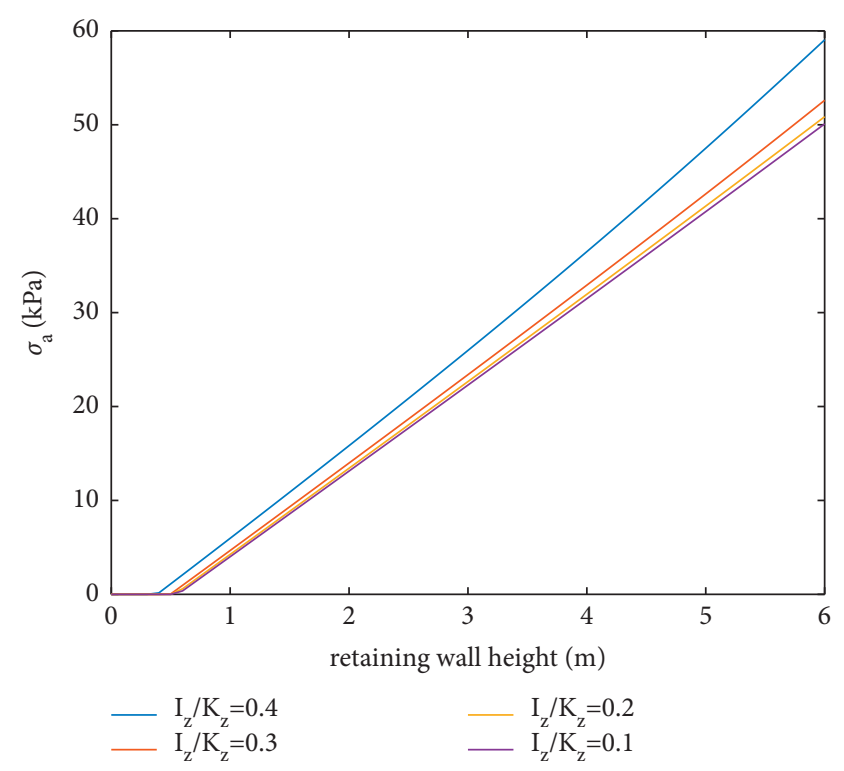

Figure 6: Changes in $\sigma_{p}$ at different marking infiltration rates.

with increasing retaining wall height and reaches a maximum at the bottom of the wall.

\section{Conclusions}

(1) Based on the traditional Coulomb earth pressure theory, combined with Iverson analysis and the shear strength formula of unsaturated soil, the active earth pressure formula of unsaturated soil was derived by 
using the thin layer element method, and the change in active earth pressure of unsaturated soil under rainfall was discussed with calculation examples.

(2) The active soil pressure of unsaturated soil without considering rainfall is lower than that of unsaturated soil when considering rainfall. With the increase in rainfall infiltration time, the active soil pressure of unsaturated soil considering rainfall increases first, then decreases and finally tends to be stable.

(3) Under rainfall, the active soil pressure of unsaturated soil changes with the standardized infiltration rate. The higher the standardized infiltration rate is, the greater the active soil pressure. This is due to the change in matric suction in unsaturated soil caused by rainfall.

(4) On the basis of the thin layer element method, the influence of matric suction and shear strength of unsaturated soil on the stress of the element is considered, and a formula for calculating the active soil pressure of unsaturated soil considering rainfall conditions is derived by using the static equilibrium equation of the element. The influence of rainfall conditions on the active soil pressure of unsaturated soil is compared and discussed by using example calculations, which can provide some reference for a follow-up study on soil pressure infiltration of unsaturated soil.

\section{Data Availability}

Some data used to support the results of this study are included within the article. Other data used to support the results of this study can be obtained from the authors.

\section{Conflicts of Interest}

The authors declare that they have no conflicts of interest.

\section{Acknowledgments}

This research was supported by the National Natural Science Foundation of China (Grant no. 51609081).

\section{References}

[1] R. M. Iverson, "Landslide triggering by rain infiltration," Water Resources Research, vol. 36, no. 7, pp. 1897-1910, 2000.

[2] D. J. Wang, L. Y. Tong, and Y. F. Qiu, "Rankine's earth pressure analysis of unsaturated soil under condition of rainfall infiltration," Yantu Lixue/rock \& Soil Mechanics, vol. 34, no. 11, pp. 3192-3196, 2013.

[3] J. H. Zhao, J. Yin, C. G. Zhang, and D. W. Chao, "Unified solution of rankine's earth pressure of unsaturated soil under rainfall," Journal of Architecture and Civil Engineering, vol. 33, no. 02, pp. 1-6, 2016.

[4] Y. Wang, S. Z. Ma, H. B. Jia, and C. J. Ren C, "Calculation and analysis on rankine's earth pressure of unsaturated soil in rainfall and evaporation conditions," Journal of Yangtze River Scientific Research Institute, vol. 34, no. 11, pp. 96-100, 2017.
[5] X. L. Wang, G. F. Li, J. DU, and X. F. Wu, "The influence of rainfall and evaporation on the unsaturated soil pressure," Chinese Journal of Applied Mechanics, vol. 31, no. 03, pp. 423-493, 2014.

[6] X. Chen and G. L. Guo, "Active earth pressure strength model of unsaturated soil," Journal of Heilongiiang University of Science and Technology, vol. 26, no. 06, pp. 700-704, 2016.

[7] R. Q. Xu, Q. H. Zhang, X. Liu, and B. Liao, "Methods for calculating soil-water pressure considering permeability," Chinese Journal of Geotechnical Engineering, vol. 34, no. 05, pp. 961-964, 2012.

[8] W. Z. Zhong and H. Ma, "Analysis of active earth pressure in unsaturated soil considering soil arching effect under One-dimensional steady flow," Railway Engineering, vol. 59, no. 12, pp. 109-113, 2019.

[9] H. Li, J. Q. Wu, R. Hou, and Z. Q. Huang, "Experimental study on one - step outflow test for rapid determination of SWCC," Yangtze River, vol. 51, no. 02, pp. 160-165, 2020.

[10] M. Y. Pu, K. S. Zhu, and L. J. Wang, "Research on lateral earth pressure from expansive soil acting on retaining wall under rain infiltration," YELLOW RIVER, vol. 37, no. 11, pp. 125-128, 2015.

[11] X. Chen, D. W. Cheng, and H. Guo, "Active earth pressure model of unsaturated cohesionless soil considering the nonlinear distribution of suction stress," Chinese Journal of Underground Space and Engineering, vol. 15, no. 04, pp. 167-173, 2019. 